\title{
Choosing Wisely Canada - pediatric otolaryngology recommendations
}

\author{
Mitchell McDonough ${ }^{1 \dagger}$, Kalpesh Hathi ${ }^{1 \dagger}$, Gerard Corsten ${ }^{2}$, Christopher J. Chin ${ }^{1,2}$, Paolo Campisi ${ }^{3}$, \\ Jonathan Cavanagh ${ }^{4}$, Neil Chadha ${ }^{5}$, M. Elise Graham ${ }^{6}$, Murad Husein ${ }^{6}$, Liane B. Johnson², Jodi Jones ${ }^{7}$, \\ Bruce Korman ${ }^{8}$, John Manoukian ${ }^{9}$, Lily H. P. Nguyen ${ }^{9}$, Doron D. Sommer ${ }^{8}$, Julie Strychowsky ${ }^{6}$, Trina Uwiera ${ }^{10}$, \\ Warren Yunker ${ }^{11}$ and Paul Hong ${ }^{2^{*}}$
}

\begin{abstract}
The Choosing Wisely Canada campaign raises awareness amongst physicians and patients regarding unnecessary or inappropriate tests and treatments. Using an online survey, members of the Pediatric Otolanyngology Subspecialty Group within the Canadian Society of Otolaryngology - Head \& Neck Surgery developed a list of nine evidence based recommendations to help physicians and patients make treatment decisions regarding common pediatric otolaryngology presentations: (1) Don't routinely order a plain film x-ray in the evaluation of nasal fractures; (2) Don't order imaging to distinguish acute bacterial sinusitis from an upper respiratory infection; (3) Don't place tympanostomy tubes in most children for a single episode of otitis media with effusion of less than 3 months duration; (4) Don't routinely prescribe intranasal/ systemic steroids, antihistamines or decongestants for children with uncomplicated otitis media with effusion; (5) Don't prescribe oral antibiotics for children with uncomplicated tympanostomy tube otorrhea or uncomplicated acute otitis externa; (6) Don't prescribe codeine for post-tonsillectomy/adenoidectomy pain relief in children; (7) Don't administer perioperative antibiotics for elective tonsillectomy in children; (8) Don't perform tonsillectomy for children with uncomplicated recurrent throat infections if there have been fewer than 7 episodes in the past year, 5 episodes in each of the past 2 years, or 3 episodes in each of the last 3 years; and (9) Don't perform endoscopic sinus surgery for uncomplicated pediatric chronic rhinosinusitis prior to failure of maximal medical therapy and adenoidectomy.
\end{abstract}

Keywords: Pediatric otolaryngology, Choosing Wisely Canada, Health care utilization, Best practice, Otitis media with effusion, Tonsillectomy

\section{Introduction}

Delivery of efficient healthcare has become increasingly important. The Choosing Wisely Canada campaign raises awareness amongst physicians and patients regarding unnecessary or inappropriate tests and treatments. The Canadian Society of Otolaryngology - Head \& Neck Surgery (CSOHNS) is a proud partner of Choosing Wisely Canada

\footnotetext{
* Correspondence: Paul.Hong@iwk.nshealth.ca

${ }^{\dagger}$ Mitchell McDonough and Kalpesh Hathi contributed equally to this work. ${ }^{2}$ Division of Otolaryngology - Head \& Neck Surgery, Department of Surgery, Dalhousie University, 5850/5920 University Ave, Halifax, Nova Scotia B3K 6R8 PO Box 9700, Canada

Full list of author information is available at the end of the article
}

and has previously released recommendations for Head and Neck Surgical Oncology [1], Otology/Neurotology [2], and Rhinology [3].

The CSOHNS is dedicated to improving patient care through the support of education, promotion of research, dissemination of information, scientific advancement of the society, and the maintenance of high professional and ethical standards. The Pediatric Otolaryngology Subspecialty Group (POSG) of the CSOHNS maintains these same core values and strives to promote evidence-based care amongst physicians and patients through the development of a Choosing Wisely Canada recommendation list.

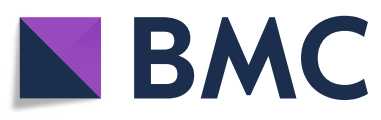

(c) The Author(s). 2021 Open Access This article is licensed under a Creative Commons Attribution 4.0 International License, which permits use, sharing, adaptation, distribution and reproduction in any medium or format, as long as you give appropriate credit to the original author(s) and the source, provide a link to the Creative Commons licence, and indicate if changes were made. The images or other third party material in this article are included in the article's Creative Commons licence, unless indicated otherwise in a credit line to the material. If material is not included in the article's Creative Commons licence and your intended use is not permitted by statutory regulation or exceeds the permitted use, you will need to obtain permission directly from the copyright holder. To view a copy of this licence, visit http://creativecommons.org/licenses/by/4.0/. The Creative Commons Public Domain Dedication waiver (http://creativecommons.org/publicdomain/zero/1.0/) applies to the data made available in this article, unless otherwise stated in a credit line to the data. 
Pediatric otolaryngology complaints are commonly seen in many different settings. These recommendations aim to reduce unnecessary or inappropriate tests or treatments and may be relevant to various providers including general practitioners and otolaryngologists encountering pediatric otolaryngology patients.

\section{Methods}

The current list was created by members of the POSG of the CSOHNS. Members were chosen based on their ongoing affiliation with an academic teaching hospital and their subspecialty training in pediatric otolaryngology. An initial list of 25 recommendations regarding unnecessary tests and interventions were compiled, along with sourced material to support the recommendations. Members of the group, considered to be national leaders within the subspecialty, were then asked to complete an electronic survey providing feedback on each recommendation and ranking their merit. The survey was constructed using Opinio (ObjectPlanet Inc., Oslo, Norway).

Each recommendation was rated by individual PSOG members based on five commonly evaluated factors: potential to affect clinical practice, cost-benefit ratio, potential to cause harm, evidence supporting recommendation, and pervasiveness of test/intervention [4]. A scale of 1-9 was used, with 1-3 indicating low impact/not relevant, 46 as uncertain, and 7-9 indicating high impact/high relevance. In addition, each recommendation had a comment section for respondents to input feedback, as well as a question asking if the recommendation should be included in the final list (yes, no, uncertain). The results of the survey were used to rank the 25 recommendations based on highest overall score, and comments were used to revise or reject certain recommendations. Based on this, nine recommendations had general consensus of merit and moved on to a panel review for final editing. The list was circulated to members of the POSG for approval. These recommendations were peer reviewed and subsequently released on the Choosing Wisely Canada website, as well promoted through Twitter and an email campaign.

\section{Results}

Don't routinely order a plain film x-ray in the evaluation of pediatric nasal fractures

Nasal fractures are one of the most common facial fractures in the pediatric population [5]. The decision to perform a closed reduction procedure for an uncomplicated nasal fracture in the operating room is based on factors such as breathing difficulty and external deformity, which are not assessed effectively by $x$-ray [6]. Plain film $\mathrm{x}$-rays are unable to accurately evaluate nasal fractures given its low sensitivity and specificity, at 72 and $73 \%$ respectively [6]. Physical examination is often sufficient to make a diagnosis for children with displaced nasal fractures [7]. Overall, $\mathrm{x}$-rays do not add value to the diagnosis or treatment plan for children with nasal fractures and should not be ordered to avoid their associated costs and radiation exposure.

\section{Don't order imaging to distinguish acute bacterial sinusitis from an upper respiratory infection}

Uncomplicated acute bacterial sinusitis (ABS) is a diagnosis that is made based on clinical criteria and has a low prevalence amongst children presenting with respiratory symptoms [8-10]. Although a normal $\mathrm{x}$-ray, $\mathrm{CT}$, or MRI can help to rule out ABS, an abnormal result does not confirm the diagnosis [8]. Given that many children will have abnormal findings on imaging due to viral upper respiratory infections and/or other inflammatory diseases during certain times of the year, combined with the potential for radiation exposure, imaging is not routinely recommended $[11,12]$. Instances in which imaging would be warranted include if the child is immunocompromised, or if orbital, central nervous system, or suppurative complications are present [8].

The American Academy of Pediatrics recommends diagnosing pediatric ABS when a child with an acute upper respiratory tract infection presents with (1) persistent illness (nasal discharge [of any quality] or daytime cough or both lasting more than 10 days without improvement), (2) a worsening course (worsening or new onset of nasal discharge, daytime cough, or fever after initial improvement), or (3) severe onset (concurrent fever [temperature $\geq 39^{\circ} \mathrm{C} / 102.2^{\circ} \mathrm{F}$ ] and purulent nasal discharge for at least 3 consecutive days) [8].

\section{Don't place tympanostomy tubes in children for a single episode of uncomplicated otitis media with effusion of less than 3 months' duration}

Although tympanostomy tube insertion can be associated with short-term quality of life improvements, the natural history of otitis media with effusion (OME) is sufficiently favorable and the majority of uncomplicated OME cases in children will spontaneously resolve within 3 months [13-15]. Cases of OME lasting longer than 3 months are typically chronic in nature, and less likely to resolve without intervention $[13,16]$. Limited data exists regarding the efficacy of tympanostomy tube insertion in children with OME for less than 3 months. By delaying the consideration for tympanostomy tube insertion, potentially unnecessary procedures are avoided, along with the associated risks, tube related side effects, and costs [16]. Children who present with a single episode of uncomplicated OME should be reassessed at 3 months and 6 months for indications for intervention [13]. Children excluded from this recommendation include those who have risk factors for developmental difficulties such as trisomy 21, autism-spectrum disorder, craniofacial 
disorders, blindness, other developmental delays and permanent hearing loss independent of OME [13].

Don't routinely prescribe intranasal/systemic steroids, antihistamines or decongestants for children with uncomplicated otitis media with effusion

In most cases, medical treatment using antihistamines, decongestants, systemic antibiotics and steroids have shown little to no effect on the long-term outcomes of uncomplicated OME in children [17-19]. In addition, there are associated costs and potential side effects of these medications [20]. Therefore, the recommendation is not to routinely prescribe these medical treatments for children with uncomplicated OME. The exception to this would be for children with coexisting conditions in which these medications are indicated for primary management (e.g., children with allergic rhinitis) [17].

\section{Don't prescribe oral antibiotics for children with uncomplicated tympanostomy tube otorrhea or uncomplicated acute otitis externa}

The use of unnecessary oral antibiotics can promote antibiotic resistance and increase the risk of opportunistic infections [21]. Topical antibiotics achieve higher concentrations in the ear canal and middle ear, demonstrate improved patient satisfaction, are associated with fewer adverse events, and are shown to have equal efficacy for treatment of acute tympanostomy tube otorrhea (TTO) and acute otitis externa (AOE) when compared to oral antibiotics [21-25]. For these reasons, topical antibiotics rather than oral antibiotics should be prescribed as first line treatment for acute uncomplicated TTO and uncomplicated AOE.

\section{Don't prescribe codeine for post-tonsillectomy/ adenoidectomy pain relief in children}

Codeine has been associated with a high rate of adverse drug reactions in children [26, 27]. This includes lifethreatening respiratory depression [28, 29]. Appropriate dosing of codeine is challenging due to the genetic heterogeneity amongst patients for the CYP2D6 enzyme, which is responsible for codeine metabolism [26, 30]. Genetic screening of CYP2D6 is not routinely performed and cannot reliably identify variations in codeine metabolism rates among patients $[26,30]$. As such, children who are ultra-fast metabolizers of codeine are placed at increased risk of severe adverse drug reactions $[28,29]$. Alternative analgesia should be used post-tonsillectomy/ adenoidectomy. Providers should be aware that other analgesics could also have active metabolites which may be of concern in children at an inappropriate dose (e.g., morphine).
Don't administer perioperative antibiotics for elective tonsillectomy in children

Administration of perioperative antibiotics for children undergoing elective uncomplicated tonsillectomy shows no significant benefits in regard to common posttonsillectomy morbidities [31, 32]. Overuse of systemic antibiotics increases bacterial resistance and the risk of adverse drug events unnecessarily. These concerns outweigh the reduction in postoperative fever which is the only potential benefit of perioperative antibiotic administration for elective tonsillectomy [31, 32]. Therefore, perioperative antibiotics are not recommended for children undergoing elective tonsillectomy, unless specific indications are present (e.g., cardiac conditions or those with a peritonsillar abscess or active infection) [31].

\section{Don't perform tonsillectomy for children with} uncomplicated recurrent throat infections if there have been fewer than 7 episodes in the past year, 5 episodes in each of the past 2 years, or 3 episodes in each of the last 3 years

For children who have a lower number of recurrent throat infections, tonsillectomy has significantly less benefit when compared to those with more frequent infections, and many children with recurrent throat infections naturally improve without intervention [33, 34]. Therefore, where safely possible, avoidance of tonsillectomy for children with lower number of acute infections is recommended [35]. This avoids unnecessary tonsillectomy and the costs and complications associated with the procedure (e.g., bleeding, pain, infection) [33, 34]. If tonsillectomy is not indicated, children should be closely monitored and reconsidered for tonsillectomy if the infection frequency increases, as they would be less likely to naturally improve, and more likely to benefit from tonsillectomy. Families should be counselled on the limited benefits and potential harms of performing tonsillectomy for children and adolescents with low rates of recurrent throat infections [35]. Shared decision making is of importance when considering tonsillectomy as individual patient and family factors can impact the decision. Providers should take into account the clinical features and severity of throat infections and social factors (e.g., missed school days) relevant to the individual patient and family. Exceptions to this recommendation include patients with recurrent peritonsillar abscesses, PFAPA (Periodic Fever, Aphthous Stomatitis, Pharyngitis, Adenitis), severe infections, rheumatic heart disease or Lemierre's syndrome [35].

\section{Don't perform endoscopic sinus surgery for} uncomplicated pediatric chronic rhinosinusitis prior to failure of maximal medical therapy and adenoidectomy While endoscopic sinus surgery (ESS) has been found to be an effective therapy in children with uncomplicated 
chronic rhinosinusitis, comparable outcomes can be achieved with medical therapy and adenoidectomy [36, 37]. A stepwise approach of medical therapy, progressing to adenoidectomy, then to ESS allows children to be treated with less invasive and more cost-effective interventions as initial therapy, while saving ESS for those who are refractory to primary interventions [37, 38]. Maximal medical therapy should be exhausted prior to surgical intervention for uncomplicated patients [3739]. In cases with complications such as orbital or skull base involvement, ESS can be employed more readily.

\section{Discussion}

These recommendations are not hard "rules" but are rather intended to promote discussion amongst physicians and patients regarding evidence-based approaches to reduce inappropriate or unnecessary treatment for pediatric otolaryngology patients. Relevance for patients revolves primarily around providing a concise description as to why practitioners may opt for or against certain treatments. In addition to these recommendations being open access on their website, Choosing Wisely Canada actively promotes their campaigns through social media and posters for use in clinicians' offices, both of which patients may be exposed to. Clinicians should carefully tailor treatments and discussions with patients based on each individual patient's unique presentation and circumstances. These recommendations are not meant to establish payment or coverage by insurers.

\section{Abbreviations \\ ABS: Acute Bacterial Sinusitis; AOE: Acute Otitis Externa; CT: Computed Tomography; CSOHNS: Canadian Society of Otolaryngology- Head \& Neck Surgery; ESS: Endoscopic Sinus Surgery; MRI: Magnetic Resonance Imaging; OME: Otitis Media with Effusion; PFAPA: Periodic Fever, Aphthous Stomatitis, Pharyngitis, Adenitis; POSG: Pediatric Otolaryngology Subspecialty Group; TTO: Tympanostomy Tube Otorrhea}

\section{Acknowledgements}

Thank you to Choosing Wisely Canada for their guidance and critical review of the recommendations. Thank you to all members of the CSOHNS Pediatric Otolaryngology Subspecialty Group.

\section{Authors' contributions \\ Authors $\mathrm{KH}$ and $\mathrm{MM}$ contributed equally to this manuscript and are therefore listed as co-first authors. \\ $\mathrm{PH}$ initiated the manuscript and was the contact person with Choosing Wisely Canada. PH, GC, CJC, MM and KH created the initial list of recommendations. $\mathrm{KH}$ and $\mathrm{MM}$ performed an extensive literature review surrounding the recommendations, created the surveys for distribution and analyzed the results. All authors contributed to the ranking and revising of the recommendations. $\mathrm{PH}, \mathrm{GC}, \mathrm{CJC}, \mathrm{MM}$, and $\mathrm{KH}$ all contributed to drafting the manuscript. All authors read and approved the final manuscript.}

\section{Authors' information}

Not applicable.

Funding

Not applicable.

Availability of data and materials Not applicable.

\section{Declarations}

Ethics approval and consent to participate

Not applicable.

\section{Consent for publication}

Not applicable.

\section{Competing interests}

The authors declare that they have no competing interests.

\section{Author details}

'Dalhousie Medicine New Brunswick, Saint John, New Brunswick, Canada. ${ }^{2}$ Division of Otolaryngology - Head \& Neck Surgery, Department of Surgery, Dalhousie University, 5850/5920 University Ave, Halifax, Nova Scotia B3K 6 R8 PO Box 9700, Canada. ${ }^{3}$ Department of Otolaryngology - Head \& Neck Surgery, University of Toronto, Toronto, Ontario, Canada. ${ }^{4}$ Division of Otolaryngology - Head \& Neck Surgery, Department of Surgery, Memorial University of Newfoundland, St. John's, Newfoundland and Labrador, Newfoundland, Canada. ${ }^{5}$ Division of Otolaryngology - Head \& Neck Surgery, Department of Surgery, University of British Columbia, Vancouver, British Columbia, Canada. ${ }^{6}$ Department of Otolaryngology - Head \& Neck Surgery, Western University, London, Ontario, Canada. ${ }^{7}$ Department of Otolaryngology - Head \& Neck Surgery, University of Manitoba, Winnipeg, Manitoba, Canada. ${ }^{8}$ Department of Surgery, Otolaryngology/Head \& Neck Surgery Division, McMaster University, Hamilton, Ontario, Canada. ${ }^{9}$ Division of Otolaryngology - Head \& Neck Surgery, Department of Surgery, McGill University, Montreal, Quebec, Canada. ${ }^{10}$ Division of Otolaryngology - Head \& Neck Surgery, Department of Surgery, University of Alberta, Edmonton, Alberta, Canada. ${ }^{11}$ Section of Otolaryngology - Head \& Neck Surgery, Department of Surgery, University of Calgary, Calgary, Alberta, Canada.

Received: 17 February 2021 Accepted: 19 July 2021

Published online: 29 October 2021

\section{References}

1. Eskander A, Monteiro E, O'Connell D, et al. Head and Neck Surgical Oncology Choosing Wisely Campaign: imaging for patients with hoarseness, fine needle aspiration for neck mass, and ultrasound for odynophagia. J of Otolaryngol Head Neck Surg. 2018;47(2). https://doi.org/10.1186/s40463-0170251-X.

2. Ma AK, Nedzelski J, Chen J, et al. Otology/Neurotology recommendations Choosing Wisely campaign. J of Otolaryngol Head Neck Surg. 2019;48(60). doi:https://doi.org/10.1186/s40463-019-0381-4.

3. Arnstead N, Chan Y, Kilty S, et al. Choosing Wisely Canada rhinology recommendations. J of Otolaryngol Head Neck Surg. 2020;49(10). https:// doi.org/10.1186/s40463-020-00406-9.

4. Choosing Wisely Canada. Medical Professional Society Handbook. 2019. Version 1.2.

5. Desrosiers AE 3rd, Thaller SR. Pediatric nasal fractures: evaluation and management. J Craniofac Surg. 2011;22(4):1327-9. https://doi.org/10.1097/ SCS.0b013e31821c932d.

6. Mohammadi A, Ghasemi-Rad M. Nasal bone fracture--ultrasonography or computed tomography? Med Ultrason. 2011;13(4):292-5.

7. Nigam A, Goni A, Benjamin A, Dasgupta AR. The value of radiographs in the management of the fractured nose. Arch Emerg Med. 1993;10(4):293-7. https://doi.org/10.1136/emj.10.4.293.

8. Wald ER, Applegate KE, Bordley C, Darrow DH, Glode MP, Marcy SM, et al. Clinical practice guideline for the diagnosis and management of acute bacterial sinusitis in children aged 1 to 18 years. Pediatrics. 2013;132(1): e262-80. https://doi.org/10.1542/peds.2013-1071.

9. Wald ER, Nash D, Eickhoff J. Effectiveness of amoxicillin/clavulanate potassium in the treatment of acute bacterial sinusitis in children. Pediatrics. 2009;124(1):9-15. https://doi.org/10.1542/peds.2008-2902.

10. Aitken M, Taylor JA. Prevalence of clinical sinusitis in young children followed up by primary care pediatricians. Arch Pediatr Adolesc Med. 1998; 152(3):244-8. https://doi.org/10.1001/archpedi.152.3.244.

11. Kristo A, Uhari M, Luotonen J, Koivunen P, Illkko E, Tapiainen T, et al. Paranasal sinus findings in children during respiratory infection evaluated with magnetic resonance imaging. Pediatrics. 2003;111(5 Pt 1):e586-9. https://doi.org/10.1542/peds.111.5.e586. 
12. Gwaltney JM Jr, Phillips CD, Miller RD, Riker DK. Computed tomographic study of the common cold. N Engl J Med. 1994;330(1):25-30. https://doi. org/10.1056/NEJM199401063300105.

13. Rosenfeld RM, Schwartz SR, Pynnonen MA, Tunkel DE, Hussey HM, Fichera JS, et al. Clinical practice guideline: tympanostomy tubes in children. Otolaryngol Head Neck Surg. 2013;149(1):S1-35. https://doi.org/10.1177/01 94599813487302.

14. Hellstrom S, Groth A, Jorgensen F. Ventilation tube treatment: a systematic review of the literature. Otolaryngol Head Neck Surg. 2011;145(3):383-95. https://doi.org/10.1177/0194599811409862.

15. Lous J, Burton MJ, Felding JU, Ovesen T, Rovers MM, Williamson I. Grommets (ventilation tubes) for hearing loss associated with otitis media with effusion in children. Cochrane Database Syst Rev. 2005;1:CD001801.

16. Rosenfeld RM, Kay D. Natural history of untreated otitis media. Laryngoscope. 2003;113(10):1645-57. https://doi.org/10.1097/00005537-2 00310000-00004

17. Rosenfeld RM, Shin JJ, Schwartz SR, Coggins R, Gagnon L, Hackell JM, et al. Clinical practice guideline: otitis media with effusion (update). Otolaryngol Head Neck Surg. 2016;154(1 Suppl):S1-S41. https://doi.org/10.1177/0194 599815623467.

18. Simpson SA, Lewis R, van der Voort J, Butler CC. Oral or topical nasal steroids for hearing loss associated with otitis media with effusion in children. Cochrane Database Syst Rev. 2011;5:CD001935. https://doi.org/10.1 002/14651858.CD001935.pub3.

19. Griffin G, Flynn CA. Antihistamines and/or decongestants for otitis media with effusion (OME) in children. Cochrane Database Syst Rev. 2011;9: CD003423.

20. Venekamp RP, Burton MJ, van Dongen TM, van der Heijden GJ, van Zon A, Schilder AG. Antibiotics for otitis media with effusion in children. Cochrane Database Syst Rev. 2016;6:CD009163. https://doi.org/10.1002/14651858. CD009163.pub3.

21. Goldblatt EL, Dohar J, Nozza RJ, Nielsen RW, Goldberg T, Sidman JD, et al. Topical ofloxacin versus systemic amoxicillin/clavulanate in purulent otorrhea in children with tympanostomy tubes. Int J Pediatr Otorhinolaryngol. 1998;46(1-2):91-101. https://doi.org/10.1016/S01655876(98)00150-5.

22. Rosenfeld RM, Schwartz SR, Pynnonen MA, Tunkel DE, Hussey HM, Fichera JS, et al. Clinical practice guideline: tympanostomy tubes in children. Otolaryngol Head Neck Surg. 2013;149(1 Suppl):S1-35. https://doi.org/10.11 77/0194599813487302.

23. Rosenfeld RM, Schwartz SR, Cannon CR, Roland PS, Simon GR, Kumar KA, et al. Clinical practice guideline: acute otitis externa. Otolaryngol Head Neck Surg. 2014;150(1):S1-S24. https://doi.org/10.1177/0194599813517083.

24. Kaushik V, Malik T, Saeed SR. Interventions for acute otitis externa. Cochrane Database of Syst Rev. 2010;6(2):444-560. https://doi.org/10.1002/14651858. CD004740.pub2

25. Rosenfeld RM, Singer M, Wasserman JM, Stinnett SS. Systematic review of topical antimicrobial therapy for acute otitis externa. Otolaryngol Head Neck Surg. 2006;134(4_suppl):S24-48. https://doi.org/10.1016/j.otohns.2006.02.013.

26. Mitchell RB, Archer SM, Ishman SL, Rosenfeld RM, Coles S, Finestone SA, et al. Clinical practice guideline: tonsillectomy in children (update). Otolaryngol Head Neck Surg. 2019;160(1 Suppl):S1-42. https://doi.org/10.11 77/0194599818801757.

27. Prows CA, Zhang X, Huth MM, Zhang K, Saldaña SN, Daraiseh NM, et al. Codeine-related adverse drug reactions in children following tonsillectomy: a prospective study. Laryngoscope. 2014;124(5):1242-50. https://doi.org/10.1 002/lary.24455.

28. Kelly LE, Rieder M, van den Anker J, Malkin B, Ross C, Neely MN, et al. More codeine fatalities after tonsillectomy in north American children. Pediatrics. 2012;129(5):e1343-7. https://doi.org/10.1542/peds.2011-2538.

29. Tobias JD, Green TP, Coté CJ. Codeine: time to say no. Pediatrics. 2016; 138(4):e20162396. https://doi.org/10.1542/peds.2016-2396.

30. Crews KR, Gaedigk A, Dunnenberger HM, Leeder JS, Klein TE, Caudle KE, et al. Clinical pharmacogenetics implementation consortium guidelines for cytochrome P450 2D6 genotype and codeine therapy: 2014 update. Clin Pharmacol Ther. 2014;95(4):376-82. https://doi.org/10.1038/clpt.2013.254.

31. Mitchell RB, Archer SM, Ishman SL, Rosenfeld RM, Coles S, Finestone SA, et al. Clinical practice guideline: tonsillectomy in children (update). Otolaryngol Head Neck Surg. 2019;160(1 Suppl):S1-42. https://doi.org/10.11 77/0194599818801757
32. Dhiwakar M, Clement WA, Supriya M, McKerrow WS. Antibiotics to reduce post-tonsillectomy morbidity. Cochrane Database Syst Rev. 2008;2: CD005607. https://doi.org/10.1002/14651858.CD005607.pub2.

33. Burton MJ, Glasziou PP, Chong LY, Venekamp RP. Tonsillectomy or adenotonsillectomy versus non-surgical treatment for chronic/recurrent acute tonsillitis. Cochrane Database Syst Rev. 2014;11:CD001802. https://doi. org/10.1002/14651858.CD001802.pub3.

34. Francis DO, Chinnadurai S, Sathe NA, Morad A, Jordan AK, Krishnaswami S et al. Tonsillectomy for obstructive sleep-disordered breathing or recurrent throat infection in children. Rockville (MD): Agency for Healthcare Research and Quality (US); 2017:Report No:16(17)-EHC042-EF.

35. Mitchell RB, Archer SM, Ishman SL, Rosenfeld RM, Coles S, Finestone SA, et al. Clinical practice guideline: tonsillectomy in children (update). Otolaryngol Head Neck Surg. 2019;160(1):S1-42. https://doi.org/10.1177/01 94599818801757.

36. Shetty KR, Soh HH, Kahn C, Wang R, Shetty A, Brook C, et al. Review and analysis of research trends in surgical treatment of pediatric chronic sinusitis. Am J Rhinol Allergy. 2020;34(3):428-35. https://doi.org/10.1177/194 5892419896240

37. Brietzke SE, Shin JJ, Choi S, Lee JT, Parikh SR, Pena M, et al. Clinical consensus statement: pediatric chronic rhinosinusitis. Otolaryngol Head Neck Surg. 2014;151(4):542-53. https://doi.org/10.1177/0194599814549302.

38. Rosenfeld RM. Pilot study of outcomes in pediatric rhinosinusitis. Arch Otolaryngol Head Neck Surg. 1995;121(7):729-36. https://doi.org/10.1001/a rchotol.1995.01890070015005.

39. Desrosiers M, Evans G, Keith P, Wright E, Kaplan A, Bouchard J, et al. Canadian clinical practice guidelines for acute and chronic rhinosinusitis. J Otolaryngol Head Neck Surg. 2011;40(2):S99-193.

\section{Publisher's Note}

Springer Nature remains neutral with regard to jurisdictional claims in published maps and institutional affiliations.

Ready to submit your research? Choose BMC and benefit from:

- fast, convenient online submission

- thorough peer review by experienced researchers in your field

- rapid publication on acceptance

- support for research data, including large and complex data types

- gold Open Access which fosters wider collaboration and increased citations

- maximum visibility for your research: over $100 \mathrm{M}$ website views per year

At BMC, research is always in progress.

Learn more biomedcentral.com/submissions 